\title{
Gastrointestinal Tract Involvement of Langerhans Cell Histiocytosis: Concerning Point of Diagnosis
}

\author{
Shevachut Chavananon, M.D., Pornpun Sripornsawan, M.D., \\ Thirachit Chotsampancharoen, M.D.
}

Department of Pediatrics, Faculty of Medicine, Prince of Songkla University, Hat Yai, Songkhla 90110, Thailand.

Received 18 March 2020 • Revised 17 April 2020 • Accepted 8 May 2020 • Published online 14 July 2020

\begin{abstract}
:
An 8-month-old girl presented with chronic mucous bloody diarrhea for 3 months. She was diagnosed as infective gastroenteritis and did not improve after antibiotic treatment. Three months subsequently, she was diagnosed with allergic gastroenteritis after developing generalized skin rash and was treated with amino acid-based formula but the symptoms of diarrhea deteriorated. The results of a biopsy of the gastrointestinal tract and skin lesions confirmed the diagnosis of Langerhans cell histiocytosis. Although Langerhans cell histiocytosis is uncommon with gastrointestinal tract involvement, Langerhans cell histiocytosis should be listed in the differential diagnosis for patients who present with chronic mucous bloody diarrhea that is unresponsive to multimodality treatment.
\end{abstract}

Keywords: chronic mucous bloody diarrhea, gastrointestinal tract involvement, langerhans cell histiocytosis

Contact: Assoc. Prof. Thirachit Chotsampancharoen, M.D.

Department of Pediatrics, Faculty of Medicine, Prince of Songkla University, Hat Yai 90110, Thailand.

E-mail: cthirachit@yahoo.com, cteerach@medicine.psu.ac.th

This is an open access article under the CC BY-NC-ND license

(http://www.jhsmr.org/index.php/jhsmr/about/editorialPolicies\#openAccessPolicy). 


\section{Introduction}

Langerhans cell histiocytosis ( $\mathrm{LCH}$ ) may involve many organs and can take many clinical manifestations. Gastrointestinal tract (GIT) involvement in $\mathrm{LCH}$ is very rare and may present a major clinical problem such as chronic diarrhea, protein loosing enteropathy, failure to thrive, hematochezia or melena. ${ }^{1}$ Usually, GIT involvement is most frequently associated with multisystem disease, occurrence in very young children, and half of the cases can be missed easily or result in a delayed diagnosis. ${ }^{2}$ GIT manifestations can be confused with infectious, allergic, immunodeficiency or inflammatory bowel diseases. ${ }^{3}$ In this report, we revealed a patient who presented initially with chronic mucous bloody diarrhea and then subsequently developed generalized skin rash which can cause an easily missed or delayed diagnosis of $\mathrm{LCH}$.

\section{Case report}

An 8-month-old female presented with chronic mucous bloody diarrhea. Her birth and postnatal history were unremarkable. At 1 month of age she developed recurrent mucous bloody diarrhea and intermittent emesis. She had no fever or rash or any other specific symptoms. She was diagnosed as infective gastroenteritis and treated with antibiotics off and on. All investigations for an infectious cause were negative. She was followed up at the out-patient department regularly but the symptom of diarrhea did not improve and concomitantly developed feeding intolerance over a 3-month period. Then, she subsequently developed a new-onset, widespread manifestation of scaly erythematous, seborrhea-like brown to red papules on the scalp and intertriginous zones particularly behind the ears. There was no pus discharge from the ear canal and other examinations were within normal ranges. After she had the skin rash with mucous bloody diarrhea, a pediatrician at an outside hospital diagnosed her as allergic enterocolitis secondary to cow's milk protein allergy. Despite dietary changes to amino acid-based formula and treatment for infection for a 5-month period, her clinical symptoms did not improve. She was transferred to our hospital for further investigations.

At our hospital, she otherwise acted well; her body weight was 5.1 kilograms (kg) (less than $3^{\text {rd }}$ percentile) and her height was 65 centimeters $(\mathrm{cm})$ (as $10^{\text {th }}$ percentile). The physical examination revealed that she was afebrile with mildly pale conjunctiva and no icteric sclera. Her abdomen was distended with hepatosplenomegaly. Her skin rash had spread from the forehead to her extremities, neck, and palmar creases. There were also areas of erosion and weeping lesions with development of serous crusts. A complete blood count revealed a hemoglobin level of 8.9 gram per deciliter $(\mathrm{g} / \mathrm{dL})$, platelet count of $136,000 /$ millimeter $\left(\mathrm{mm}^{3}\right)$, reticulocyte count of $8.7 \%$, and a normal white cell count of $8,900 / \mathrm{mm}^{3}$. The renal and liver function tests revealed a normal profile (aspartate aminotransferase 14 units per liter (U/), alanine aminotransferase $21 \mathrm{U} /$, total bilirubin 0.6 milligrams per deciliter (mg/dL), direct bilirubin $0.2 \mathrm{mg} / \mathrm{dL}$. The serum albumin level was $2.9 \mathrm{~g} / \mathrm{dL}$. The coagulogram was within normal limits. The immunoglobulin levels were normal values. Urine and blood cultures were negative for bacteria and fungi. The stool revealed numerous red blood cells and the occult blood test was positive but the culture and examination of the stool for ova, parasites, and bacteria were negative.

The skull and chest radiographs showed no abnormalities. A computerized tomography (CT) scan of the abdomen revealed a diffusely enlarged liver and spleen without focal lesion. The CT scan of the chest revealed 
enlarged thymus with multiple punctate calcifications which is a specific finding in $\mathrm{LCH}$, but no mediastinal lymph node enlargement. A whole body bone scan with Technetium-99m methylene diphosphonate showed no bony involvement. A bone marrow aspirate showed a normocellular marrow without evidence of $\mathrm{LCH}$.

A gastrocolonoscopy was performed and biopsies from the stomach and the first and second parts of the duodenum revealed mucosal nodules and edematous changes in the gastric mucosal wall (Figure 1). The diagnosis of $\mathrm{LCH}$ was confirmed based on the gastrointestinal (GI) biopsy findings in which the tumor involved the gastric mucosal layer and infiltrated the lamina propria. Immunohistochemistry staining of the gastric mucosa showed infiltration of cluster of differentiation (CD) 1a positive histiocytes (Figure 2). In addition, a skin biopsy was consistent with LCH cells. Immunostains of a skin biopsy were positive for S-100, CD68, and CD1a. Birbeck granules were detected by electron microscopy.

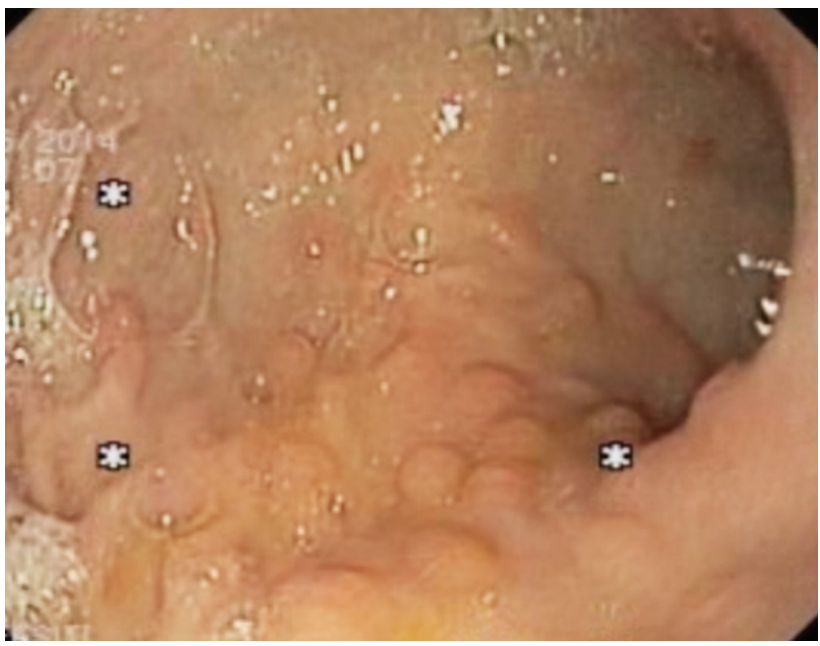

Figure 1 Gastroscopy appearance of Langerhans cell histiocytosis showing mucosal nodules with edematous changes in the gastric mucosal wal
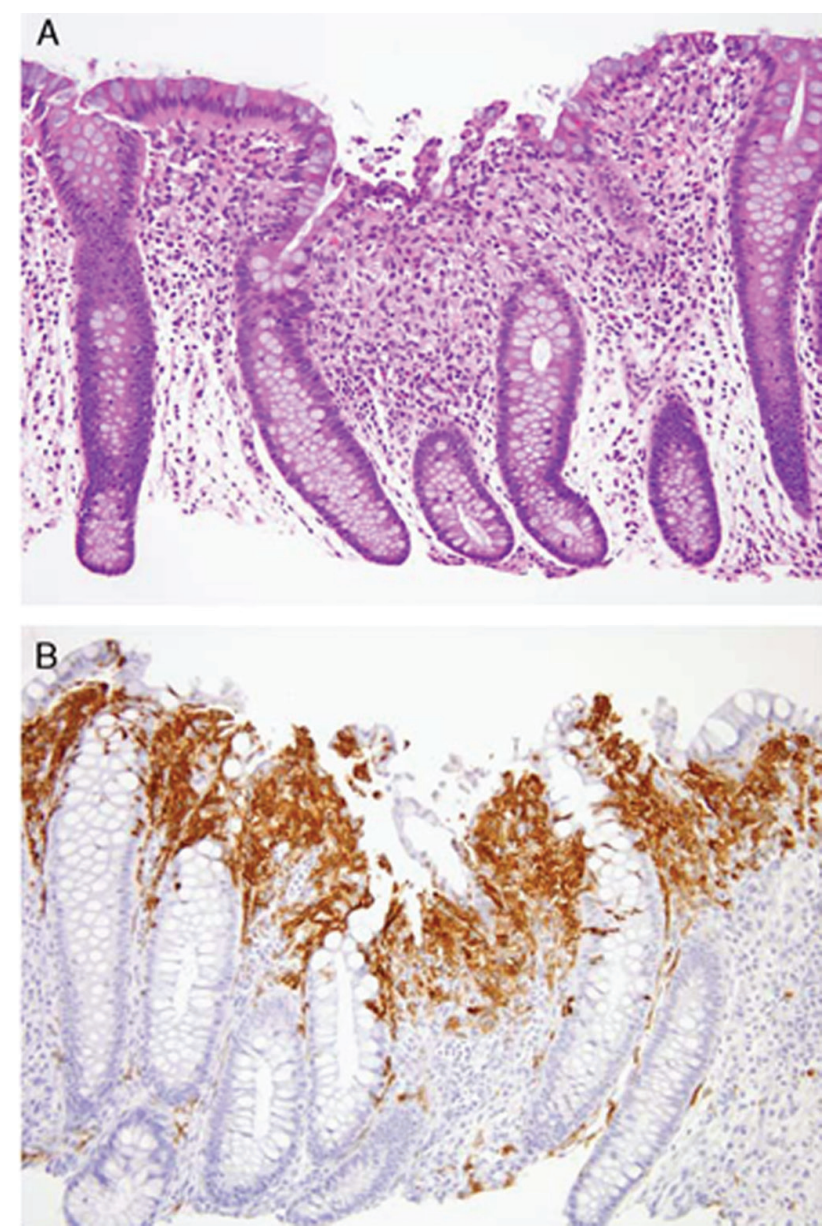

Figure 2 A: The colonic biopsy showed Langerhans cell histiocytosis which expanded to the lamina propria, separating the crypts. B: Immunohistochemistry staining of the colon mucous membrane showed infiltration of CD1a-positive histiocytes.

The child received nutritional support with total parenteral nutrition (TPN) to improve her nutritional status. Chemotherapy was started promptly. She was started on induction chemotherapy (weekly intravenous vinblastine $6 \mathrm{mg} / \mathrm{m}^{2}$ day, Etoposide $150 \mathrm{mg} / \mathrm{m}^{2} /$ day, daily oral prednisolone $40 \mathrm{mg} / \mathrm{m}^{2}$ ). After 6 weeks of induction, the patient was asymptomatic and there was no active 
disease in the GIT and skin. TPN feeding was stopped and she could tolerate oral feeding. She was treated further with maintenance therapy (continuous daily oral 6-mercaptopurine $50 \mathrm{mg} / \mathrm{m}^{2}$, prednisolone $40 \mathrm{mg} / \mathrm{m}^{2}$ for 5 days every 3 weeks, and vinblastine $6 \mathrm{mg} / \mathrm{m}^{2}$ and etoposide $150 \mathrm{mg} / \mathrm{m}^{2} /$ day every 3 weeks) for 6 months and she was good response to chemotherapy protocol. Now, she is in clinical remission for about 5 years from the end of treatment. Her clinical status is normal development for age and her body weight is $20 \mathrm{~kg}$ ( $50^{\text {th }}$ percentile), height is $106 \mathrm{~cm}$ ( $10^{\text {th }}$ percentile).

\section{Discussion}

GIT involvement in LCH is exceedingly rare with an incidence of 9 in 348 patients (2.6\%) from the French Langerhans Cell Histiocytosis Study Group between 1983 and $1994 .{ }^{4}$ We also reviewed a Medline literature search from 1966 to 2019 and were able to identify only a total of 68 pediatric cases of well-defined LCH with GIT involvement over nearly a 55-year period. Only 58 cases were reviewed from 1966 to 2010 and 10 more reported cases from 2010 to 2019 that included our case. ${ }^{2,5-10}$

In this article we described an infant who initially presented with symptoms of chronic mucous bloody diarrhea for a 3-month period without any specific signs and then subsequently developed generalized skin rash. In this setting, a diagnosis of $\mathrm{LCH}$ was missed. It is possible that patients with GIT involvement of $\mathrm{LCH}$ are being missed because of uncommon GIT involvement and a wide spectrum of clinical presentations. GIT involvement in LCH may manifest as chronic mucous bloody diarrhea, hematochezia, constipation or protein loosing enteropathy and can range in severity from mild to life-threatening.

Usually, the Gl symptoms are preceded by or associated with the characteristic $\mathrm{LCH}$ rash in $86.0 \%$ of the patients. From a study of 9 patients from the French Langerhans Cell Histiocytosis Study Group, about 5 in 9
(55.6\%) patients had a gap in time between the onset of skin manifestations and Gl symptoms of 2-11 months and only 4 in 9 (44.4\%) had simultaneous onset. ${ }^{11}$ These clinical settings can guide a diagnosis to infective or allergic gastroenteritis that results in a delay to diagnose LCH. From a literature review, about 9 in 18 cases (50.0\%) of patients with GIT involvement of $\mathrm{LCH}$ were initially diagnosed as allergic or infective gastroenteritis, inflammatory bowel disease or immunodeficiency. ${ }^{2}$

Patients with LCH and GIT involvement tend to present at a very young age. The majority of reported patients (86.0\%) were under 1 year of age and $95.0 \%$ of the patients presented before 18 months of age. ${ }^{1,3}$

It is apparent that the prognosis of LCH with GIT involvement is relatively poor. Sixty-one percent of the patients died within 24 months of diagnosis, whereas only $14.0 \%$ of the patients achieved complete remission. ${ }^{2}$ The mortality rate of $\mathrm{LCH}$ patients with GIT involvement is about $55.0 \% .^{3}$ This is in contrast to $\mathrm{LCH}$ mortality rates in general which have a $7.0 \%$ mortality rate for singlesystem and a $39.0 \%$ mortality rate for multisystem disease. ${ }^{12}$ It remains unclear if age at onset, severity of symptoms, timing of diagnosis or nutritional status contributes to the outcome. The majority of the patients with $\mathrm{LCH}$ and GIT involvement had poor nutritional status such as hypoalbuminemia and failure to thrive and most patients were diagnosed in their infancy period. These two factors may have an effect on the outcome.

There have been many regimens for treating $\mathrm{LCH}$ with GIT involvement which depend on the treatment center although the optimal approach to treatment remains unclear. Standard treatment includes corticosteroids, antimetabolites, vinca alkaloids, and cytotoxic agents. Treatment outcomes vary because only case reports are published in the literature. For our patient, we considered the two issues of age and nutritional status and decided to use the standard regimen for systemic $\mathrm{LCH}$. She 
received chemotherapy as scheduled without any serious side effects and tolerated the side effects until she completed the chemotherapy regimen. She was still alive and in clinical remission about 5 years after the diagnosis.

On the other hand, Choi, et al. $^{13}$ reported that treatment with 2-chlorodeoxyadenosine and high dose cytarabine could achieve a durable response. The French langerhans cell histiocytosis study group concluded that any GIT involvement with LCH warrants aggressive evaluation and treatment. GIT involvement of $\mathrm{LCH}$ should be treated as a multisystemic disease irrespective of the patient's clinical status. ${ }^{11}$

We need to observe and follow-up the number of patients with GIT involvement of $\mathrm{LCH}$ to determine the optimal regimen of chemotherapy. We should balance between the complications or side effects of aggressive chemotherapy with the survival rate which depends on several factors such as nutritional status and age of the patient. If we use aggressive chemotherapy for young infants who have failure to thrive or malnutrition status, the patient may get worse from the treatment.

\section{Conclusion}

We suggest that GIT involvement of $\mathrm{LCH}$ be considered on the list of the differential diagnosis for patients with chronic mucous bloody diarrhea who are unresponsive to amino acid-based formula or other treatments. Careful examination of the systemic manifestations such as skin rash or recurrent dermatitis can provide a guide in the diagnosis. The optimal treatment regimens might result in a durable long-term remission or cure.

\section{Acknowledgement}

We would like to thank Mr. Dave Leslie Patterson for his assistance with manuscript editing.

\section{Conflict of interest}

Nothing to declare

\section{References}

1. Hait E, Liang M, Degar B, Glickman J, Fox VL. Gastrointestinal tract involvement in Langerhans cell histiocytosis: case report and literature review. Pediatrics 2006;118:1593-99.

2. Shima $H$, Takahashi $T$, Shimada H. Protein-losing enteropathy caused by gastrointestinal tract-involved Langerhans cell histiocytosis. Pediatrics 2010;125:426-32.

3. Yadav SP, Kharya G, Mohan N, Sehgal A, Bhat S, Jain S, et al. Langerhans cell histiocytosis with digestive tract involvement. Pediatr Blood Cancer 2010;55:748-53.

4. The French Langerhans' Cell Histiocytosis Study Group. A multicenter retrospective survey of Langerhans' cell histiocytosis: 348 cases observed between 1983 and 1993. Arch Dis Child 1996;75:17-24.

5. Singhi AD, Montgomery EA. Gastrointestinal tract Langerhans cell histiocytosis: a clinicopathologic study of 12 patients. Am J Surg Pathol 2011;35:305-10.

6. Godoy MM, Fernandes M, Halenda GM, Javid G, Ngo PD. Gastrointestinal Langerhans cell histiocytosis. J Pediatr Gastroenterol Nutr 2014;59:17.

7. Abdullgaffar B, Al-Murbati B, Al-Falasi M, Al-Otaibi L. Unsuspected Langerhans cell histiocytosis can be easily missed in a colonic biopsy. Fetal Pediatr Pathol 2014;33:98103.

8. Barón GL, Olmedilla JM, Pérez AV, Melgar BA. Langerhans cell histiocytosis presenting as Enterocolitis and shock in neonate: J Pediatr Hematol Oncol 2019;41:155-7.

9. Vetter LS, Salinas JA, Martin SA, Guibelalde M, Ramon BP. Digestive tract symptoms in congenital Langerhans cell histiocytosis: a fatal condition in an illness usually considered benign. J Pediatr Hematol Oncol 2014;36:4.

10. Levy J, Khaskelberg A, Garvin J. Langerhans cell histiocytosis ( $\mathrm{LCH}$ ) involving the gastrointestinal tract: a clinicalelectrogastrographic correlation. J Pediatr Gastroenterol Nutr 2001;33:511-4.

11. Geissmann F, Thomas C, Emile JF, Micheau M, Canioni D, Bensussan NC, et al. Digestive tract involvement in Langerhans cell histiocytosis. The French langerhans cell histiocytosis study group. J Pediatr 1996;129:836-45. 
12. Braier J, Chantada G, Rosso D, Bernaldez P, Amaral D, Latella $A$, et al. Langerhans cell histiocytosis: retrospective evaluation of 123 patients at a single institution. Pediatr Hematol Oncol 1999;16:377-85.
13. Choi SW, Bangaru BS, Wu CD, Finlay JL. Gastrointestinal involvement in disseminated Langerhans cell histiocytosis (LCH) with durable complete response to 2-chlorodeoxyadenosine and high-dose cytarabine. J Pediatr Hematol Oncol 2003;25:503-6. 